\title{
DISCUSSÃO DA ESTRUTURA FORMAL SOBRE O RETORNO DAS EMBALAGENS DE AGROTÓXICOS: UMA REVISÃO TEÓRICA SOB OS ASPECTOS LEGAIS E DA CONSCIÊNCIA AMBIENTAL
}

\author{
Maurício Dias Marques ${ }^{1}$ \\ Sérgio Silva Braga Junior ${ }^{2}$ \\ Pedro Fernando Cataneo ${ }^{3}$
}

\section{RESUMO:}

O uso de agrotóxicos na produção agrícola acarreta problema ambiental. Visando minimizar o problema de contaminação, a legislação instituiu o retorno das embalagens dos agrotóxicos com a utilização do processo da logística reversa. 0 presente estudo tem por objetivo discutir a estrutura formal do retorno das embalagens de agrotóxicos às indústrias fabricantes para a destinação final de maneira correta sob a perspectiva de uma revisão teórica sobre os aspectos legais e da consciência ambiental dos participantes dessa cadeia. Para atender o objetivo proposto foi realizada uma pesquisa bibliográfica apresentando a legislação, as discussões sobre a mesma por diferentes autores sob a ótica da consciência ambiental que deve existir dentro da cadeia. Como resultado foi possível observar que, apesar de contribuir para a preservação do meio ambiente, trazer benefícios econômicos e evitar danos à saúde, a logística reversa imposta pela legislação implica em responsabilidades compartilhadas de todos os envolvidos no processo (o agricultor, o revendedor, a unidade de recebimento, o fabricante, o poder público), mas, pelas discussões encontradas, o maior gargalo pode estar na dificuldade de entregar as embalagens usadas nos pontos de coleta, sendo necessária uma maior participação/atuação do poder público para que todo o processo funcione adequadamente.

Palavras-chave: embalagens de agrotóxicos, logística reversa, responsabilidade compartilhada.

\footnotetext{
${ }_{1}^{1}$ Mestrando em Agronegócios e Desenvolvimento, UNESP, Tupã, e-mail: mdmarques1985@gmail.com.

${ }^{2}$ Doutor, professor do Programa de Pós-Graduação em Agronegócios e Desenvolvimento, UNESP, Tupã, e-mail: sergio@tupa.unesp.br.

${ }^{3}$ Doutor, professor e Vice-Diretor da UNESP, Tupã, e-mail: pedro@tupa.unesp.br.
} 


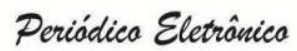 \\ Fórum Ambiental}

da Alta Paulista

\title{
DISCUSSION OF FORMAL STRUCTURE ON THE RETURN OF PESTICIDE CONTAINERS : A THEORETICAL REVIEW UNDER THE LEGAL ASPECTS AND ENVIRONMENTAL CONSCIOUSNESS
}

\begin{abstract}
:
The use of pesticides in agricultural production causes environmental problem. In order to minimize the problem of contamination, legislation established the return of pesticide packaging using the reverse logistics process. This study aims to discuss the formal structure of return of pesticide packaging to the manufacturing industries for the final correctly destination from the perspective of a theoretical review on the legal aspects and the environmental awareness of the participants of this chain. To meet the proposed objective was conducted a bibliographic research presenting the legislation, discussions on it by different authors from the perspective of environmental awareness that must exist within the chain. As a result it was observed that, despite contributing to the preservation of the environment, bring economic benefits and avoid damage to health, the reverse logistic imposed by the legislation implies shared responsibilities between all involved in the process (the farmer, the dealer, the unit receipt, the manufacturer, the government), but by the discussions, the biggest bottleneck may be in the difficulty to deliver the pesticide packagings used in the collection points, requiring greater participation / performance of the government, so that the whole process to work properly.
\end{abstract}

Keywords: pesticide packaging, reverse logistics, shared responsibility.

\section{DISCUSIÓN DE LA ESTRUCTURA FORMAL EN EL RETORNO DE ENVASES DE PLAGUICIDAS : una revisión teórica BAJO LOS ASPECTOS LEGALES Y CONCIENCIA AMBIENTAL}

\section{RESUMEN:}

El uso de plaguicidas en la producción agrícola causa problema ambiental. Con el fin de minimizar el problema de la contaminación, la legislación estableció el retorno de los envases de plaguicidas utilizando el proceso de logística inversa. Este estudio tiene como objetivo analizar la estructura formal de la devolucion de envases a las industrias manufactureras para el correcto destino desde la perspectiva de una revisión teórica sobre los aspectos jurídicos y la conciencia ambiental de los participantes de esta cadena. Para cumplir con el objetivo propuesto se llevó a cabo una investigacioón bibliográfica en que se presenta la legislación, las discusiones sobre la misma de diferentes autores desde la perspectiva de la conciencia ambiental que deben existir dentro de la cadena. Como resultado se observó que, a pesar de que contribuye a la preservación del medio ambiente, trae beneficios 
económicos y evitar daños a la salud, la logística que impone la legislación implica una responsabilidad de todos los involucrados en el proceso (el agricultor, el comerciante, el unidad receptora, el fabricante, el gobierno), pero por las discusiones, el mayor cuello de botella puede estar en dificultades para entregar los plaguicidas de envasado en los puntos de recogida, lo que requiere una mayor participación / desempeño Del gobierno para todo el proceso funcione correctamente.

Palabras clave: envases de plaguicidas, logística inversa, la responsabilidad compartida.

\section{INTRODUÇÃO}

Com o uso dos pesticidas, agroquímicos, agrotóxicos ou defensivos agrícolas, como definido por diversos autores (Veiga, 2013; Nogueira e Dantas, 2013; Oliveira e Camargo, 2014; Cometti, 2009; Ladeira, Maehler e Nascimento, 2012), suas embalagens devem ter o destino correto, ao contrario, podem causar danos ao meio ambiente e à saúde dos homens e animais. O destino final das embalagens dos agrotóxicos é um processo complexo que requer a participação efetiva de todos os envolvidos na fabricação, comercialização, utilização, licenciamento, fiscalização e monitoramento relacionados com o tratamento, transporte, armazenamento e processamento de tais embalagens.

A Política Nacional de Resíduos Sólidos (Lei 12.305/2010) estabeleceu como instrumento de desenvolvimento econômico e social a implantação de sistemas de logística reversa, consistente num conjunto de ações, procedimentos e meios destinados a viabilizar a coleta e a restituição dos resíduos sólidos ao setor empresarial, para aproveitamento em seu ciclo ou em outros ciclos produtivos, ou para destinação final ambientalmente adequada, conforme art. $3^{\circ}$, XII da Lei. A aplicação da logística reversa requer integração entre União, Estados, Municípios e particulares, que irão somar investimentos e esforços com a preocupação da conservação do meio ambiente.

A Logística Reversa do Pós-Consumo (aplicada no caso das embalagens de agrotóxicos), abrange os bens que, após serem produzidos e utilizados, passam a ser de pós-consumo, e devido a isso os mesmos podem ser enviados a destinos finais tradicionais, como por exemplo, incineração e aterros sanitários, ou também podem retornar ao ciclo produtivo, através da reciclagem ou reuso (LEITE, 2003). 
Neste contexto surge o problema que orientou a presente pesquisa: Qual o impacto da legislação que regulamenta e logística reversa de embalagens de agrotóxicos nos participantes da cadeia? Para responder o problema, o objetivo foi realizar uma pesquisa bibliográfica apresentando a legislação e as discussões sobre a mesma por diferentes autores sob a ótica da consciência ambiental que deve existir dentro da cadeia.

Como resultado, foi possível observar que, apesar dos benefícios, a logística reversa implica em responsabilidades compartilhadas de todos os envolvidos no processo, que necessitam, a partir do agricultor/consumidor, ter uma infraestrutura e fiscalização mais intensa e abrangente por parte do poder público, para que todo o processo funcione adequadamente.

\section{HISTÓRICO DA REGULAMENTAÇÃO LEGAL SOBRE AS EMBALAGENS DE AGROTÓXICOS}

Inicialmente deve-se considerar que, segundo Garcia e Garcia (2001), para aumentar a produtividade, a modernização da agricultura contou com várias tecnologias, a partir da década de 1960, entre elas os agrotóxicos. Mas, seu uso generalizado e intensivo tem gerado diversos problemas relacionados à saúde pública e ao desequilíbrio ambiental, incluindo: intoxicações de agricultores; contaminações de alimentos, de águas e de solos; resistência de espécies combatidas às substâncias empregadas e danos em espécies não visadas.

A legislação brasileira, ao longo dos anos, destinou certo cuidado com as embalagens de agrotóxicos, regulamentando confecção, apresentação, transporte, armazenamento e descarte. Um passeio pelos diplomas legais desde 1934 até a atualidade, no que tange especificamente ao descarte com o retorno das mesmas para reutilização, reciclagem ou inutilização é o que se pretende expor aqui.

O Decreto 24.114/1934, de 12/04/1934, que aprovou o regulamento de defesa sanitária vegetal, no $\S 3^{\circ}$ do art. 56 , proclamava que "será exigido de fabricantes, importadores e revendedores, embalagem condizente com os interesses do agricultor, á juízo do Serviço de Defesa Sanitária Vegetal." 
A Lei 6.360/1976, de 23/04/1976, que dispõe sobre a Vigilância Sanitária, em seu artigo 60, alertava que "é obrigatória a aprovação, pelo Ministério da Saúde, conforme se dispuser em regulamento, das embalagens, dos equipamentos e utensílios elaborados ou revestidos internamente com substâncias que, em contato com o produto, possam alterar seus efeitos ou produzir dano à saúde."

A lei 7.802/1989, de 11/07/1989, também conhecida como "Lei dos Agrotóxicos", com as alterações dadas pela Lei $9.974 / 2000$, dispõe nos parágrafos do $\S 2^{\circ}, 4^{\circ}$ e $5^{\circ}$ do art. $6^{\circ}$, o seguinte:

$\S 2^{\circ}$ Os usuários de agrotóxicos, seus componentes e afins deverão efetuar a devolução das embalagens vazias dos produtos aos estabelecimentos comerciais em que foram adquiridos, de acordo com as instruções previstas nas respectivas bulas, no prazo de até um ano, contado da data de compra, ou prazo superior, se autorizado pelo órgão registrante, podendo a devolução ser intermediada por postos ou centros de recolhimento, desde que autorizados e fiscalizados pelo órgão competente.(Incluído pela Lei $n^{\circ}$ 9.974, de 2000)

$\S 4^{0}$ As embalagens rígidas que contiverem formulações miscíveis ou dispersíveis em água deverão ser submetidas pelo usuário à operação de tríplice lavagem, ou tecnologia equivalente, conforme normas técnicas oriundas dos órgãos competentes e orientação constante de seus rótulos e bulas. (Incluído pela Lei ํㅜ 9.974, de 2000)

$\S 5^{\circ}$ As empresas produtoras e comercializadoras de agrotóxicos, seus componentes e afins, são responsáveis pela destinação das embalagens vazias dos produtos por elas fabricados e comercializados, após a devolução pelos usuários, e pela dos produtos apreendidos pela ação fiscalizatória e dos impróprios para utilização ou em desuso, com vistas à sua reutilização, reciclagem ou inutilização, obedecidas as normas e instruções dos órgãos registrantes e sanitário-ambientais competentes. (Incluído pela Lei no 9.974, de 2000)

Também essa mesma Lei, nos artigos 12A, 14 e 15, dispõe que:

Art. 12A. Compete ao Poder Público a fiscalização: (Incluído pela Lei oㅜ 9.974, de 2000)

1- da devolução e destinação adequada de embalagens vazias de agrotóxicos, seus componentes e afins, de produtos apreendidos pela ação fiscalizadora e daqueles impróprios para utilização ou em desuso; (Incluído pela Lei no 9.974, de 2000)

II - do armazenamento, transporte, reciclagem, reutilização e inutilização de embalagens vazias e produtos referidos no inciso l. (Incluído pela Lei n 9.974, de 2000)

Art. 14. As responsabilidades administrativa, civil e penal pelos danos causados à saúde das pessoas e ao meio ambiente, quando a produção, comercialização, utilização, transporte e destinação de embalagens vazias de agrotóxicos, seus componentes e afins, não cumprirem o disposto na legislação pertinente, cabem: (Redação dada pela Lei oㅜ 9.974, de 2000)

a) ao profissional, quando comprovada receita errada, displicente ou indevida;

b) ao usuário ou ao prestador de serviços, quando proceder em desacordo com o receituário ou as recomendações do fabricante e órgãos registrantes e sanitário-ambientais; (Redação dada pela Lei oㅜ 9.974, de 2000) 
c) ao comerciante, quando efetuar venda sem o respectivo receituário ou em desacordo com a receita ou recomendações do fabricante e órgãos registrantes e sanitário-ambientais; (Redação dada pela Lei oㅜ 9.974, de 2000)

d) ao registrante que, por dolo ou por culpa, omitir informações ou fornecer informações incorretas;

e) ao produtor, quando produzir mercadorias em desacordo com as especificações constantes do registro do produto, do rótulo, da bula, do folheto e da propaganda, ou não der destinação às embalagens vazias em conformidade com a legislação pertinente; (Redação dada pela Lei no 9.974, de 2000)

f) ao empregador, quando não fornecer e não fizer manutenção dos equipamentos adequados à proteção da saúde dos trabalhadores ou dos equipamentos na produção, distribuição e aplicação dos produtos.

Art. 15. Aquele que produzir, comercializar, transportar, aplicar, prestar serviço, der destinação a resíduos e embalagens vazias de agrotóxicos, seus componentes e afins, em descumprimento às exigências estabelecidas na legislação pertinente estará sujeito à pena de reclusão, de dois a quatro anos, além de multa. (Redação dada pela Lei oํ 9.974, de 2000)

Art. 16. O empregador, profissional responsável ou o prestador de senviço, que deixar de promover as medidas necessárias de proteção à saúde e ao meio ambiente, estará sujeito à pena de reclusão de 2 (dois) a 4 (quatro) anos, além de multa de 100 (cem) a 1.000 (mil) MVR. Em caso de culpa, será punido com pena de reclusão de 1 (um) a 3 (três) anos, além de multa de 50 (cinqüenta) a 500 (quinhentos) MVR.

Art. 17. Sem prejuízo das responsabilidades civil e penal cabíveis, a infração de disposições desta Lei acarretará, isolada ou cumulativamente, nos termos previstos em regulamento, independente das medidas cautelares de estabelecimento e apreensão do produto ou alimentos contaminados, a aplicação das seguintes sanções:

I - advertência;

II - multa de até 1000 (mil) vezes o Maior Valor de Referência - MVR, aplicável em dobro em caso de reincidência;

III - condenação de produto;

IV - inutilização de produto;

V - suspensão de autorização, registro ou licença;

$\mathrm{VI}$ - cancelamento de autorização, registro ou licença;

VII - interdição temporária ou definitiva de estabelecimento;

VIII - destruição de vegetais, partes de vegetais e alimentos, com resíduos acima do permitido;

IX - destruição de vegetais, partes de vegetais e alimentos, nos quais tenha havido aplicação de agrotóxicos de uso não autorizado, a critério do órgão competente.

Parágrafo único. A autoridade fiscalizadora fará a divulgação das sanções impostas aos infratores desta Lei.

O Decreto 98.816/1990, de 11/01/1990, que regulamentou a Lei 7.802/1989,

previa a seguinte regulamentação: (Lembrar que esse Decreto foi revogado pelo Decreto 4.074/2002).

Art. 33-C. Os usuários de agrotóxicos e afins deverão efetuar a devolução das embalagens vazias, e respectivas tampas, dos produtos aos estabelecimentos comerciais em que foram adquiridos, observadas as instruções estabelecidas nos rótulos e bulas, no prazo de até um ano, contado da data de sua compra. (Artigo incluído pelo Decreto no 3.550 , de $\underline{27.7 .2000)}$ 


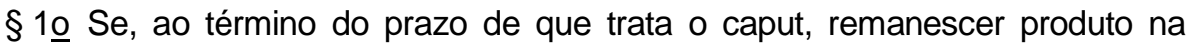
embalagem, ainda no seu prazo de validade, será facultada a devolução da embalagem no final deste prazo.

$\S 2 \underline{o}$ É facultada ao usuário a devolução das embalagens vazias a qualquer unidade de recebimento credenciada.

§ $3 \underline{0}$ Os usuários deverão manter à disposição dos órgãos fiscalizadores os comprovantes de devolução de embalagens vazias, fornecidas pelos estabelecimentos comerciais ou pelas unidades de recebimento, pelo prazo de, no mínimo, um ano, após a devolução da embalagem.

$\S 4 \underline{0}$ No caso de embalagens contendo produtos impróprios para utilização ou em desuso, o usuário observará as orientações contidas nas respectivas bulas, cabendo às empresas produtoras e comercializadoras promover $\mathrm{o}$ recolhimento e a destinação admitidos pelo órgão ambiental competente.

§ $5 \underline{0}$ As embalagens rígidas, que contiverem formulações miscíveis ou dispersíveis em água, deverão ser submetidas pelo usuário à operação de tríplice lavagem, ou tecnologia equivalente, conforme orientação constante de seus rótulos e bulas.

$\S 6 \underline{0}$ Os usuários de componentes deverão efetuar a devolução das embalagens vazias aos estabelecimentos comerciais onde foram adquiridos e, quando se tratar de produto adquirido no exterior, incumbir-se de sua destinação adequada.

Art. 33-D. Os estabelecimentos comerciais deverão dispor de instalações adequadas devidamente dimensionadas para recebimento e armazenamento das embalagens vazias devolvidas pelos usuários, até que sejam recolhidas pelas respectivas empresas produtoras e comercializadoras, responsáveis pela destinação final destas embalagens. (Artigo incluído pelo Decreto ํㅡ 3.550, de $27.7 .2000)$

$\S 1$ o Os estabelecimentos comerciais:

1- deverão disponibilizar unidades de recebimento, cujas condições de funcionamento e acesso não venham a dificultar a devolução pelos usuários, se não tiverem condições de receber ou armazenar embalagens vazias no mesmo local onde são realizadas as vendas dos produtos;

II - farão constar da nota fiscal de venda do produtos o endereço para devolução da embalagem vazia e comunicarão ao usuário, formalmente, qualquer alteração no endereço;

III - ficam obrigados a manter à disposição do serviço de fiscalização o sistema de controle das quantidades e dos tipos de embalagens adquiridas e devolvidas pelos usuários, com as respectivas datas das ocorrências.

Art. 33-E. As unidades de recebimento de embalagens vazias fornecerão comprovante de recebimento das embalagens onde deverão constar, no mínimo: (Artigo incluído pelo Decreto no 3.550, de 27.7.2000)

I - nome da pessoa física ou jurídica que efetuou a devolução;

II - data do recebimento;

III - quantidades e tipos de embalagens recebidas; e

IV-nomes das empresas responsáveis pela destinação final das embalagens.

Art. 33-G. As empresas produtoras de agrotóxicos, seus componentes e afins são responsáveis pelo recolhimento, transporte e pela destinação final das embalagens vazias, devolvidas pelos usuários aos estabelecimentos comerciais ou às unidades de recebimento, e dos produtos por elas fabricados e comercializados: (Artigo incluído pelo Decreto no 3.550 , de 27.7.2000)

I - apreendidos pela ação fiscalizatória;

II - impróprios para utilização ou em desuso, com vistas à sua reciclagem ou inutilização, de acordo com normas e instruções dos órgãos registrante e sanitário-ambientais competentes. 
$\S 1 \underline{0}$ As empresas registrantes e produtoras de agrotóxicos e afins podem instalar e manter postos ou centros de recolhimento de embalagens usadas e vazias.

§ 20 As empresas produtoras de componentes estabelecidas no País são responsáveis pelo recebimento e destinação final adequada das embalagens vazias que contiveram produtos por elas produzidas.

$\S 3 \underline{0}$ O prazo para recolhimento e destinação final das embalagens pelas empresas registrantes e produtoras é de, no máximo, um ano, a contar data de devolução pelos usuários.

$\S 4 \underline{0}$ Os responsáveis por postos e centros de recolhimento de embalagens vazias deverão manter à disposição dos órgãos de fiscalização sistema de controle das quantidades e dos tipos de embalagens recebidas e encaminhadas à destinação final." (NR)

Art. 33-H. Quando o produto não for fabricado no País a pessoa física ou jurídica responsável pela importação assumirá, com vistas a reutilização, reciclagem ou inutilização, a responsabilidade pela destinação: (Artigo incluído pelo Decreto $n^{\circ} 3.550$, de 27.7.2000)

1-das embalagens vazias dos produtos importados e comercializados, após a devolução pelos usuários;

II-dos produtos apreendidos pela ação fiscalizatória e dos impróprios para utilização ou em desuso.

Parágrafo único. Tratando-se de produto importado submetido a processamento industrial ou a novo acondicionamento, caberá ao órgão registrante definir a responsabilidade de que trata o caput.

Art. 45. Somente empresa produtora de agrotóxicos, componentes ou afins, e mediante aprovação dos órgãos federais intervenientes no processo de registro, poderá efetuar a reutilização de embalagens. (Redação dada pelo Decreto $\mathrm{n}^{\circ}$ 3.550, de 27.7.2000)

Art. 46. 0 descarte de embalagens e resíduos de agrotóxicos e afins deverá atender às recomendações técnicas apresentadas na bula, relativas aos processos de incineração, enterro e outros, observadas as exigências dos setores de saúde, agricultura e meio ambiente.

Art. 57. Serão objeto de inspeção e fiscalização, com vistas ao controle, os agrotóxicos, seus componentes e afins, sua produção, os veículos destinados ao transporte, o armazenamento, a comercialização, a utilização, a propaganda comercial, a rotulagem e a disposição final de resíduos e embalagens.

Art. 72. As responsabilidades administrativa, civil e penal pelos danos causados à saúde das pessoas e ao meio ambiente, quando a produção, manipulação, comercialização, utilização, transporte e a destinação de embalagens vazias de agrotóxicos, seus componentes e afins não cumprirem o disposto na legislação pertinente, recairão sobre: (Redação dada pelo Decreto ํㅜ 3.550, de 27.7.2000)

I - o registrante que, por dolo ou por culpa, omitir informações ou fornece-las incorretamente;

II - o produtor, quando produzir mercadorias em desacordo com as especificações constantes do registro do produto, do rótulo, da bula e da propaganda, ou não der destinação às embalagens vazias em conformidade com a legislação pertinente. (Redação dada pelo Decreto n- 3.550, de 27.7.2000)

III - o profissional que receitar a utilização de agrotóxicos e afins de forma errada, displicente ou indevida;

IV - o comerciante, quando efetuar a venda sem o respectivo receituário ou em desacordo com a receita ou recomendações do fabricante e órgãos registrantes e sanitário-ambientais; (Redação dada pelo Decreto ํㅜ 3.550, de 27.7.2000)

$\mathrm{V}$ - o empregador que não fornecer ou não fizer a manutenção dos equipamentos de proteção individual do trabalhador ou não proceder à 


\begin{abstract}
manutenção dos equipamentos destinados à produção, distribuição e aplicação dos agrotóxicos e afins; e

$\mathrm{VI}$ - o usuário ou o prestador de serviços, quando proceder em desacordo com o receituário ou as recomendações do fabricante e órgãos registrantes e sanitário-ambientais. (Redação dada pelo Decreto no 3.550 , de 27.7.2000)

Art. 119-B. As empresas produtoras e comercializadoras de agrotóxicos, seus componentes e afins deverão: (Incluído pelo Decreto ํㅡ 3.550, de 27.7.2000)

1-estruturar-se adequadamente para as operações de recebimento, recolhimento e destinação de embalagens vazias e produtos de que trata este Decreto, até 31 de maio de 2001; (Redação dada pelo Decreto $\mathrm{n}^{\circ}$ 3.694, de 21.12.2000)

1 -estruturar-se adequadamente para as operações de recebimento, recolhimento e destinação de embalagens vazias e produtos de que trata este Decreto, até 31 de maio de 2002. (Redação dada pelo Decreto oㅡ 3.828, de 31.05.2001)

III - implementar, em colaboração com o Poder Público, medidas transitórias para orientação dos usuários quanto ao atendimento às exigências previstas neste Decreto, enquanto se realizam as adequações dos estabelecimentos comerciais e dos rótulos e bulas." (NR)
\end{abstract}

Segue-se a Lei 9.974/2000, de 06/06/2000, que altera a Lei oํ 7.802/1989, criando responsabilidades, cujas disposições alteradas já foram citadas acima na abordagem daquela lei.

Demorou-se um ano e meio para que viesse à tona o Decreto $\mathrm{n}^{0}$ 4.074/2002, de 04/01/2002, que regulamentou a "Lei dos Agrotóxicos", o qual traz algumas novas disciplinas, a saber:

Art. $1^{\circ}$ Para os efeitos deste Decreto, entende-se por:

$\mathrm{V}$ - centro ou central de recolhimento - estabelecimento mantido ou credenciado por um ou mais fabricantes e registrantes, ou conjuntamente com comerciantes, destinado ao recebimento e armazenamento provisório de embalagens vazias de agrotóxicos e afins dos estabelecimentos comerciais, dos postos de recebimento ou diretamente dos usuários;

XIX - inspeção - acompanhamento, por técnicos especializados, das fases de produção, transporte, armazenamento, manipulação, comercialização, utilização, importação, exportação e destino final dos agrotóxicos, seus componentes e afins, bem como de seus resíduos e embalagens;

XXX - posto de recebimento - estabelecimento mantido ou credenciado por um ou mais estabelecimentos comerciais ou conjuntamente com os fabricantes, destinado a receber e armazenar provisoriamente embalagens vazias de agrotóxicos e afins devolvidas pelos usuários;

Art. 51. Mediante aprovação dos órgãos federais intervenientes no processo de registro, a empresa produtora de agrotóxicos, componentes ou afins poderá efetuar a reutilização de embalagens.

Art. 52. A destinação de embalagens vazias e de sobras de agrotóxicos e afins deverá atender às recomendações técnicas apresentadas na bula ou folheto complementar.

Art. 53. Os usuários de agrotóxicos e afins deverão efetuar a devolução das embalagens vazias, e respectivas tampas, aos estabelecimentos comerciais em que foram adquiridos, observadas as instruções constantes dos rótulos e das bulas, no prazo de até um ano, contado da data de sua compra. 
$\S 1^{\circ}$ Se, ao término do prazo de que trata o caput, remanescer produto na embalagem, ainda no seu prazo de validade, será facultada a devolução da embalagem em até 6 meses após o término do prazo de validade.

$\S 2^{\circ}$ É facultada ao usuário a devolução de embalagens vazias a qualquer posto de recebimento ou centro de recolhimento licenciado por órgão ambiental competente e credenciado por estabelecimento comercial.

§ $3^{0}$ Os usuários deverão manter à disposição dos órgãos fiscalizadores os comprovantes de devolução de embalagens vazias, fornecidas pelos estabelecimentos comerciais, postos de recebimento ou centros de recolhimento, pelo prazo de, no mínimo, um ano, após a devolução da embalagem.

$\S 4^{0}$ No caso de embalagens contendo produtos impróprios para utilização ou em desuso, o usuário observará as orientações contidas nas respectivas bulas, cabendo às empresas titulares do registro, produtoras e comercializadoras, promover o recolhimento e a destinação admitidos pelo órgão ambiental competente.

$\S 5^{\circ}$ As embalagens rígidas, que contiverem formulações miscíveis ou dispersíveis em água, deverão ser submetidas pelo usuário à operação de tríplice lavagem, ou tecnologia equivalente, conforme orientação constante de seus rótulos, bulas ou folheto complementar.

$\S 6^{\circ}$ Os usuários de componentes deverão efetuar a devolução das embalagens vazias aos estabelecimentos onde foram adquiridos e, quando se tratar de produto adquirido diretamente do exterior, incumbir-se de sua destinação adequada.

Art. 54. Os estabelecimentos comerciais deverão dispor de instalações adequadas para recebimento e armazenamento das embalagens vazias devolvidas pelos usuários, até que sejam recolhidas pelas respectivas empresas titulares do registro, produtoras e comercializadoras, responsáveis pela destinação final dessas embalagens.

$\S 1^{\circ}$ Se não tiverem condições de receber ou armazenar embalagens vazias no mesmo local onde são realizadas as vendas dos produtos, os estabelecimentos comerciais deverão credenciar posto de recebimento ou centro de recolhimento, previamente licenciados, cujas condições de funcionamento e acesso não venham a dificultar a devolução pelos usuários.

$\S 2^{\circ}$ Deverá constar na nota fiscal de venda dos produtos o endereço para devolução da embalagem vazia, devendo os usuários ser formalmente comunicados de eventual alteração no endereço.

Art. 55. Os estabelecimentos comerciais, postos de recebimento e centros de recolhimento de embalagens vazias fornecerão comprovante de recebimento das embalagens onde deverão constar, no mínimo:

I - nome da pessoa física ou jurídica que efetuou a devolução;

II - data do recebimento; e

III - quantidades e tipos de embalagens recebidas.

Parágrafo único. Deverá ser mantido à disposição dos órgãos de fiscalização referidos no art. 71 sistema de controle das quantidades e dos tipos de embalagens recebidas em devolução, com as respectivas datas.

Art. 56. Os estabelecimentos destinados ao desenvolvimento de atividades que envolvam embalagens vazias de agrotóxicos, componentes ou afins, bem como produtos em desuso ou impróprios para utilização, deverão obter licenciamento ambiental.

Art. 57. As empresas titulares de registro, produtoras e comercializadoras de agrotóxicos, seus componentes e afins, são responsáveis pelo recolhimento, pelo transporte e pela destinação final das embalagens vazias, devolvidas pelos usuários aos estabelecimentos comerciais ou aos postos de recebimento, bem como dos produtos por elas fabricados e comercializados:

I - apreendidos pela ação fiscalizatória; e 
II - impróprios para utilização ou em desuso, com vistas à sua reciclagem ou inutilização, de acordo com normas e instruções dos órgãos registrante e sanitário-ambientais competentes.

$\S 1^{\circ}$ As empresas titulares de registro, produtoras e comercializadoras de agrotóxicos e afins, podem instalar e manter centro de recolhimento de embalagens usadas e vazias.

$\S 2^{\circ}$ O prazo máximo para recolhimento e destinação final das embalagens pelas empresas titulares de registro, produtoras e comercializadoras, é de um ano, a contar da data de devolução pelos usuários.

$\S 3^{\circ}$ Os responsáveis por centros de recolhimento de embalagens vazias deverão manter à disposição dos órgãos de fiscalização sistema de controle das quantidades e dos tipos de embalagens, recolhidas e encaminhadas à destinação final, com as respectivas datas.

Art. 58. Quando o produto não for fabricado no País, a pessoa física ou jurídica responsável pela importação assumirá, com vistas à reutilização, reciclagem ou inutilização, a responsabilidade pela destinação:

I-das embalagens vazias dos produtos importados e comercializados, após a devolução pelos usuários; e

II - dos produtos apreendidos pela ação fiscalizatória e dos impróprios para utilização ou em desuso.

Parágrafo único. Tratando-se de produto importado submetido a processamento industrial ou a novo acondicionamento, caberá ao órgão registrante definir a responsabilidade de que trata o caput.

Art.59. Os agrotóxicos, seus componentes e afins, e suas embalagens, apreendidos por ação fiscalizadora terão seu destino final estabelecido após a conclusão do processo administrativo, a critério da autoridade competente, cabendo à empresa titular de registro, produtora e comercializadora a adoção das providências devidas e, ao infrator, arcar com os custos decorrentes.

Parágrafo único. Nos casos em que não houver possibilidade de identificação ou responsabilização da empresa titular de registro, produtora ou comercializadora, o infrator assumirá a responsabilidade e os custos referentes a quaisquer procedimentos definidos pela autoridade fiscalizadora.

Art. 60. As empresas produtoras e as comercializadoras de agrotóxicos, seus componentes e afins deverão estruturar-se adequadamente para as operações de recebimento, recolhimento e destinação de embalagens vazias e produtos de que trata este Decreto até 31 de maio de 2002.

Art. 63. O transporte de agrotóxicos, seus componentes e afins está sujeito às regras e aos procedimentos estabelecidos na legislação específica.

Parágrafo único. O transporte de embalagens vazias de agrotóxicos e afins deverá ser efetuado com a observância das recomendações constantes das bulas correspondentes.

Art. 70. Serão objeto de inspeção e fiscalização os agrotóxicos, seus componentes e afins, sua produção, manipulação, importação, exportação, transporte, armazenamento, comercialização, utilização, rotulagem e a destinação final de suas sobras, resíduos e embalagens.

Art. 84. As responsabilidades administrativa, civil e penal pelos danos causados à saúde das pessoas e ao meio ambiente, em função do descumprimento do disposto na legislação pertinente a agrotóxicos, seus componentes e afins, recairão sobre:

I - o registrante que omitir informações ou fornecê-las incorretamente;

II - o produtor, quando produzir agrotóxicos, seus componentes e afins em desacordo com as especificações constantes do registro;

III - o produtor, o comerciante, o usuário, o profissional responsável e o prestador de serviços que opuser embaraço à fiscalização dos órgãos competentes ou que não der destinação às embalagens vazias de acordo com a legislação;

Art. 85. São infrações administrativas: 
I- pesquisar, experimentar, produzir, prescrever, fracionar, embalar e rotular, armazenar, comercializar, transportar, fazer propaganda comercial, utilizar, manipular, importar, exportar, aplicar, prestar serviço, dar destinação a resíduos e embalagens vazias de agrotóxicos, seus componentes e afins em desacordo com o previsto na Lei $n^{\circ} 7.802$, de 1989 , e legislação pertinente;

Por fim, a Resolução CONAMA (Conselho Nacional do Meio Ambiente) ํo 334, de 03/04/2003, dispõe sobre os procedimentos de licenciamento ambiental dos estabelecimentos destinados ao recebimento de embalagens vazias de agrotóxicos (revogada pela Resolução CONAMA 465/2014). Define as unidades de recebimento, controle e armazenamento das embalagens, a saber:

Art. 2o Para efeito desta Resolução serão adotadas as seguintes definições: I - posto: unidade que se destina ao recebimento, controle e armazenamento temporário das embalagens vazias de agrotóxicos e afins, até que as mesmas sejam transferidas à central, ou diretamente à destinação final ambientalmente adequada;

II - central: unidade que se destina ao recebimento, controle, redução de volume, a condicionamento e armazenamento temporário de embalagens vazias de agrotóxicos e afins, que atenda aos usuários, estabelecimentos comerciais e postos, até a retirada das embalagens para a destinação final, ambientalmente adequada;

III - unidade volante: veículo destinado à coleta regular de embalagens vazias de agrotóxicos e afins para posterior entrega em posto, central ou local de destinação final ambientalmente adequada;

IV - estabelecimento comercial: local onde se realiza a comercialização de agrotóxicos e afins, responsável pelo recebimento, controle e armazenamento das embalagens vazias de agrotóxicos nele vendidas.

Já a nova Resolução, Resolução CONAMA № 465/2014, de 05/12/2014, volta a repetir definições e critérios de localização, construção, instalação, modificação e operação de posto e de central de recebimento de embalagens de agrotóxicos, como se pode ver no art. $2^{\circ}$ :

Art. $2^{\circ}$ Para efeito desta Resolução serão adotadas as seguintes definições: I - posto: unidade que se destina ao recebimento, controle e armazenamento temporário das embalagens de agrotóxicos e afins, vazias ou contendo resíduos, até que as mesmas sejam transferidas à central ou diretamente à destinação final ambientalmente adequada;

II - central: unidade que se destina ao recebimento, controle, redução de volume, acondicionamento e armazenamento temporário de embalagens de agrotóxicos e afins, vazias ou contendo resíduos, que atenda aos consumidores, estabelecimentos comerciais e postos, até a retirada das embalagens e resíduos para a destinação final ambientalmente adequada;

III - unidade volante: veículo destinado à coleta regular de embalagens de agrotóxicos e afins, vazias ou contendo resíduos, para posterior entrega em posto, central ou local de destinação final ambientalmente adequada; e

IV - estabelecimento comercial: local onde se realiza a comercialização de agrotóxicos e afins, responsável pelo recebimento, controle e armazenamento temporário das embalagens de agrotóxicos e afins, vazias ou contendo resíduos. 


\title{
DISCUSSÃO DA LEGISLAÇÃO PERANTE A POLÍTICA NACIONAL DE RESÍDUOS SÓLIDOS E O DESTINO FINAL DAS EMBALAGENS DE AGROTÓXICOS
}

Antes de discutir propriamente a legislação sobre o retorno das embalagens de agrotóxicos, seria de bom alvitre lembrar, com Nogueira e Dantas (2013), que a Lei no 9.605, de 12/02/1998 (Lei da Natureza - lei dos crimes ambientais), como legislação destinada a coibir práticas denominadas criminosas, em seu artigo 54, proclama que é crime ambiental causar poluição de qualquer natureza em níveis tais que possam resultar em danos à saúde humana, ou que provoquem a mortandade de animais ou a destruição significativa da flora. Se o crime acontecer por lançamento de resíduos sólidos, líquidos ou gasosos, ou detritos, óleos ou substâncias oleosas em desacordo com as exigências estabelecidas em leis ou regulamentos a pena de reclusão é de 1 a 5 anos.

Esses mesmos autores comentam que a Política Nacional de Resíduos Sólidos formula a assistência da saúde pública e a qualidade do meio ambiente; a promoção dos 3RS (reduzir, reutilizar, reciclar); o tratamento e destinação final dos resíduos de modo apropriado. Ainda colocam:

\begin{abstract}
O surgimento de produtos químicos empregados no combate às pragas da lavoura representou grande progresso na agricultura, sobretudo naquela em grande escala, trazendo consigo um novo conceito de produção. O conjunto de produtos químicos recebeu as denominações de defensivos agrícolas, pesticidas, praguicidas, produtos fitossanitários ou agrotóxicos. (NOGUEIRA; DANTAS, 2013, p. 24).
\end{abstract}

Segundo Cometti (2009), somente em 1976, com a publicação da Lei 6.360/76, o Ministério da Saúde passa a preocupar-se com a saúde pública perante os defensivos agrícolas.

Em 1989 a Lei 7.802/89, conhecida como "Lei de Agrotóxicos", regulamentada pelo Decreto 98.816/1990, tratou da pesquisa, experimentação, fabricação, registro, comercialização, aplicação, controle, fiscalização de agrotóxicos, etc. Essa lei define agrotóxicos como:

os produtos e os agentes de processos físicos, químicos ou biológicos, destinados ao uso nos setores de produção, no armazenamento e beneficiamento de produtos agrícolas, nas pastagens, na proteção de florestas, nativas ou implantadas, e de outros ecossistemas e também de ambientes urbanos, hídricos e industriais, cuja finalidade seja alterar a composição da flora e da fauna, a fim de preservá-la da ação danosa de seres vivos considerados nocivos; substância e produtos empregados como 
desfolhantes, dessecantes, estimuladores e inibidores de crescimento (LEI № 7.802, ART. 20, 1989).

Em 1992 foi criado o "Programa Nacional de Recolhimento e Destinação Final Adequada de Embalagens Vazias de Agrotóxicos, sob a coordenação do IBAMA, tendo a participação de vários órgãos federais e estaduais: MAPA (Ministério da Agricultura, Pecuária e Abastecimento), ANVISA (Agência Nancional de Vigilância Sanitária), SINDAG (Sindicato Nacional da Indústria de Produtos para a Defesa Agrícola), AENDA (Associação de Empresas Fabricantes de Agrotóxicos), ANDEF (Associação Nacional de Defesa Vegetal), ANDAV (Associação Nacional dos Distribuidores de Defensivos Agrícolas), OCB (Organização das Cooperativas Brasileiras), dentre outros.

Somente com a alteração da Lei dos Agrotóxicos pela Lei 9.974/2000, regulamentada pelo Decreto 4.074/2002, foram incorporadas responsabilidades e competências legais compartilhadas a todos os atores envolvidos, sobre a destinação das embalagens vazias de agrotóxicos.

Segundo Garcia e Garcia (2001), a importância de instrumentos legais para controle de substâncias perigosas é indiscutível. A chamada "Lei dos Agrotóxicos", Lei 7802/89, que tem em foco o controle das substâncias químicas empregadas para o controle de pragas e doenças da agricultura, tem sua importância especial porquanto a legislação básica que antes estava em vigor era de 1934, época em que não se empregavam os produtos organossintéticos como agrotóxicos.

Apesar da legislação estabelecer obrigações e normalizações para as embalagens de agrotóxicos, só em 2010 é que a Lei 12.205/2010 instituiu a Política Nacional de Resíduos Sólidos. Essa lei destaca como objetivos a não geração, redução, reutilização, reciclagem e tratamento dos resíduos sólidos (art. 7º II). Prevê também como um dos instrumentos da PNRS os sistemas de logística reversa (art. 8º, II) e, no artigo $3^{\circ}$, XII, entende a logística reversa como: instrumento de desenvolvimento econômico e social caracterizado por um conjunto de ações, procedimentos e meios destinados a viabilizar a coleta e a restituição dos resíduos sólidos ao setor empresarial, para reaproveitamento, em seu ciclo ou em outros ciclos produtivos, ou outra destinação final ambientalmente adequada.

Mazza et al (2014, p. 690/691), registram que: 
Conforme o Plano Nacional de Resíduos Sólidos, os Resíduos Agrossilvopastoris são os produzidos nas atividades de agricultura, pecuária e silvicultura, e podem ser divididos em: Orgânicos - originados nas sobras de biomassa das colheitas e das criações de bovinos, suínos, aves e outros animais; Inorgânicos - tratam das embalagens produzidas nos segmentos de agrotóxicos, de fertilizantes e de insumos farmacêuticos veterinários, incluindo os resíduos sólidos domésticos (RSD) oriundos do âmbito rural. As embalagens de agrotóxicos são consideradas de alto risco e possuem um grande potencial de contaminação ambiental e humana.

Segundo Melo et al (2012) a Lei 7.802/89 passou por modificações, em 2000, pela Lei 9.974/2000 e em 2002, pelo Decreto 4.074/2002, legislação em vigor até os dias atuais. Essa legislação distribui competências e responsabilidades entre consumidores, comerciantes, fabricantes e Poder Público.

A Lei $n^{0} 7.802 / 1989$, alterada pela Lei o 9.974/2000, caracteriza os processos e os atores envolvidos no sistema de retorno e destinação final das embalagens de agrotóxicos no Brasil. Cometti (2009), define os atores: os fabricantes, os comerciantes, os agricultores e o poder público. E os processos: a fabricação, comercialização, manuseio das embalagens pelo agricultor até a sua devolução, o armazenamento, transporte e destinação final, que pode ser a reciclagem ou a incineração. O poder público participa desse processo com a fiscalização e educação ambiental conjunta com o fabricante.

Esse pesquisador (Cometti, 2009), apresenta o seguinte fluxograma:

Figura 1: Atores e respectivas responsabilidades no sistema de destinação final de embalagens de agrotóxicos no Brasil.

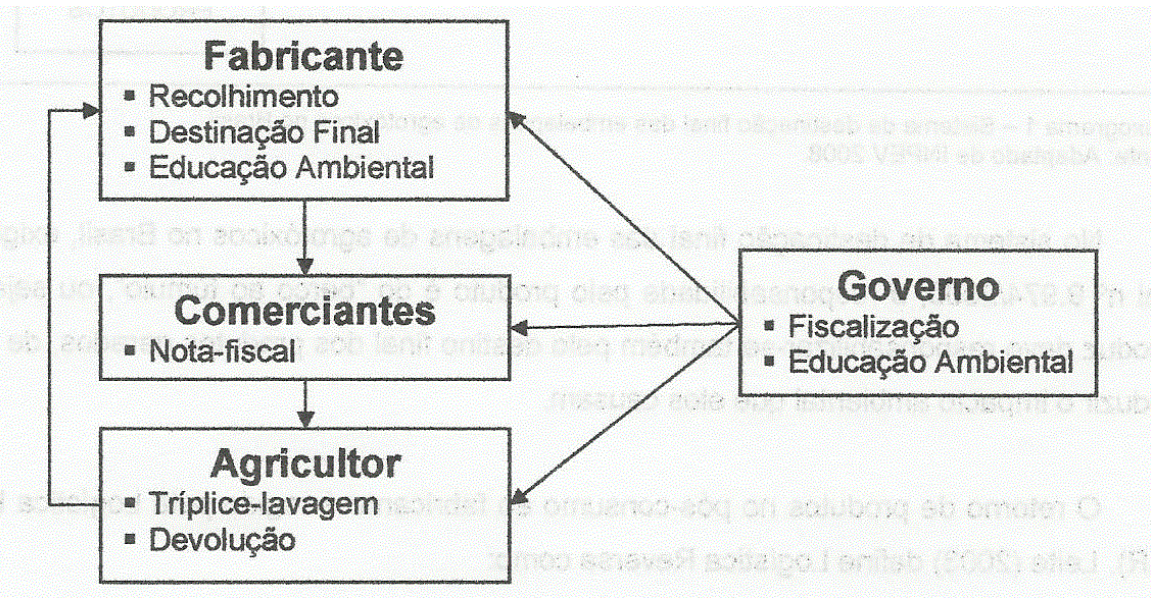

Fonte: COMETTI, 2009, p. 23 
Ainda, de acordo com Cometti (2009, p. 65/67), o Decreto ㄲo 4.074/2002, que regulamentou a Lei $7.802 / 89$ alterada pela Lei $9.974 / 00$, estabelece as seguintes responsabilidades, cuja transcrição se faz abaixo:

Aos usuários dos agrotóxicos - agricultores:

- preparar as embalagens vazias para devolvê-las nas unidades de recebimento (embalagens rígidas laváveis: efetuar a lavagem das embalagens - tríplice lavagem ou lavagem sob pressão; embalagens rígidas não laváveis: mantê-las intactas, adequadamente tampadas e sem vazamento; embalagens flexíveis contaminadas: acondicioná-las em sacos plásticos padronizados);

- inutilizar a embalagem evitando seu reaproveitamento;

- armazenar, temporariamente, as embalagens vazias na propriedade em local adequado;

- transportar e devolver as embalagens vazias, com suas respectivas tampas, no estabelecimento onde foi adquirido o produto ou na unidade de recebimento indicada na nota fiscal, no prazo de até um ano contado da data de sua compra;

- manter em seu poder os comprovantes de entrega das embalagens e a nota fiscal de compra do produto por um ano.

Aos canais de distribuição, ou revendedores de agrotóxicos:

- dispor de local adequado para o recebimento e armazenamento temporário das embalagens vazias dos agricultores ou ser credenciado a uma unidade de recebimento;

- no ato da venda do produto, informar aos agricultores sobre os procedimentos de lavagem, acondicionamento, armazenamento, transporte e devolução das embalagens vazias;

- informar o endereço da unidade de recebimento de embalagens vazias para o usuário, desde que as condições de acesso não prejudiquem a devolução pelo agricultor;

- fazer constar, nos receituários que emitirem, as informações sobre destino final das embalagens;

- implementar, em colaboração com o poder público, programas educativos e mecanismos de controle e estímulo à lavagem das embalagens vazias de agrotóxicos e à devolução das mesmas; 
- estabelecer parcerias entre si, ou com outras entidades, para a implantação e o gerenciamento das unidades de recebimento das embalagens vazias.

Aos fabricantes de agrotóxicos:

- providenciar o recolhimento, transporte e destinação final ambientalmente adequada das embalagens vazias, devolvidas pelos usuários aos estabelecimentos comerciais ou unidades de recebimento, no prazo de um ano a contar da data de devolução pelos agricultores;

- implementar, em colaboração com o poder público, programas educativos e mecanismos de controle e estímulo à lavagem e à devolução das embalagens vazias por parte dos usuários;

- alterar os modelos de rótulos e bulas para que constem neles informações sobre os procedimentos de lavagem, armazenamento, transporte, devolução e destinação final das embalagens vazias.

Ao poder público:

- fiscalizar o funcionamento do sistema de destinação final;

- emitir as licenças de funcionamento para as revendas e unidades de recebimento de acordo com os órgãos competentes de cada estado;

- apoiar os esforços de educação e conscientização do agricultor quanto às suas responsabilidades dentro do processo.

Por sua vez, Melo et al (2012), fazem um comentário das atribuições e responsabilidades dos elos do canal de distribuição reversa, do que se pode extrair: O consumidor: o primeiro elo do canal, com as responsabilidades de preparar as embalagens para devolução, realizando uma tríplice lavagem nas embalagens, perfurá-las inutilizando-as, armazená-las provisoriamente em sua propriedade em local devidamente apropriado. Se não laváveis, manter ilesas e devidamente tampadas. E, no prazo de um ano, a partir da data da compra, entregá-las na unidade de recebimento, com as respectivas tampas e rótulos.

O comerciante: responsabilidades de informar na nota fiscal o local de entrega das embalagens vazias, disponibilizar e controlar o local de recebimento, emitir comprovante de devolução das embalagens, orientar e informar o consumidor sobre o produto e suas responsabilidades. Pode receber as embalagens vazias, armazenar adequadamente e encaminhar para as unidades de recebimento. 
As unidades de recebimento: responsabilidade de inspecionar as embalagens devolvidas; verificar e classificar entre lavadas e não lavadas e separar por tipo de material. Encaminhar ao destino final, para reciclagem ou incineração.

O fabricante: responsabilidade de recolher as embalagens vazias nas unidades de recebimento, oferecer uma destinação final correta, além de orientar e informar o consumidor.

Esses autores trazem a seguinte figura ilustrativa dos fluxos reversos:

Figura 2 - Logística reversa de embalagens de agrotóxicos

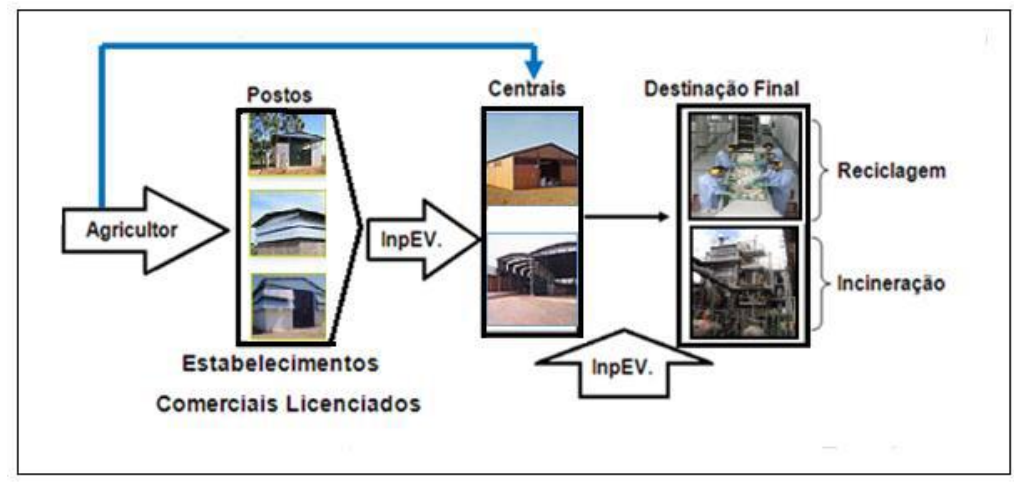

Fonte: INPEV, 2010.

À vista da regulamentação legal, criou-se, em 2002, o INPEV (Instituto Nacional de Processamento de Embalagens Vazias), organização que representa a indústria fabricante de agrotóxicos, estruturada para tratar do processamento das embalagens de agrotóxicos, que, após recolhidas, devem ser destinadas à reciclagem ou incineração. Cometti (2009), constrói o seguinte fluxo do sistema da destinação das embalagens:

Figura 3 - Sistema de destinação final das embalagens /

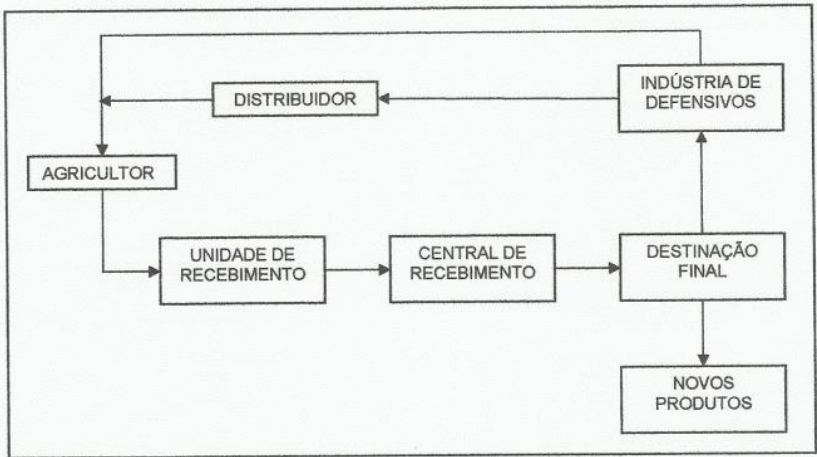

Fonte: Cometti, 2009, p. 19 (adaptado de INPEV, 2008) 
Por sua vez, Veiga (2013), descreve que o "Programa de Logística Reversa dos Resíduos de Pesticidas" é composto por oito etapas: (1) transporte para fornecedores para armazenamento temporário; (2) armazenagem em instalações de armazenagem dos fornecedores; (3) transporte para instalações de armazenamento; (4) estocagem em instalações de armazenagem; (5) transporte para o armazém central; (6) estocagem no armazém central; (7) transporte para uma instalação designada para destinação final; (8) incineração ou reciclagem. Cada uma dessas atividades está colocada na figura abaixo:

Figura 4 - Programa de Logística Reversa dos Resíduos de Pesticidas

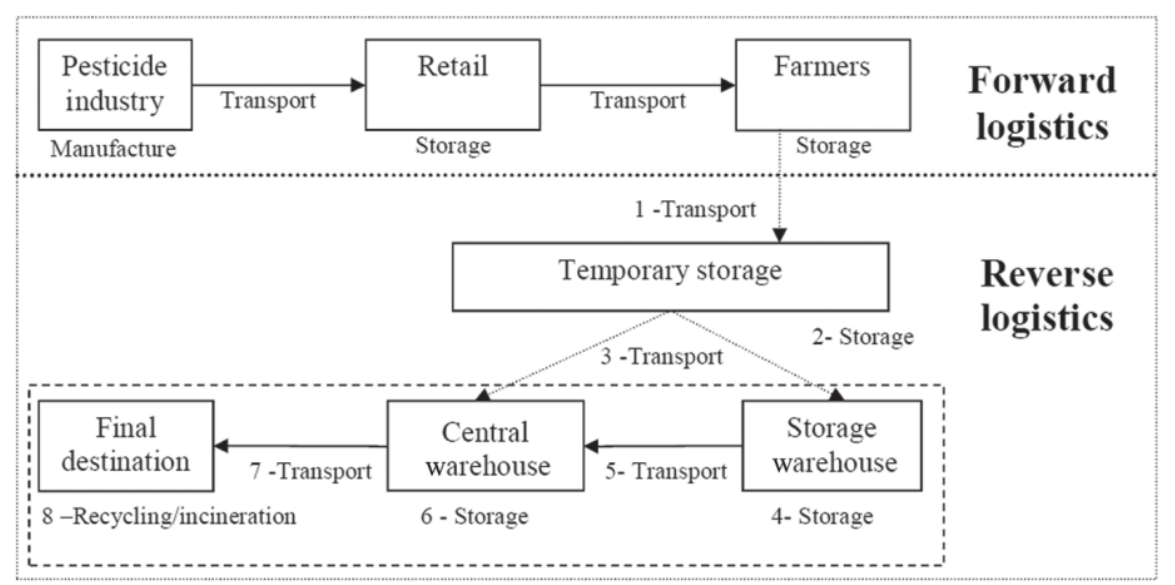

Fonte: VEIGA, 2013, p. 65

Veiga (2013), registra que, na época, o programa de logística reversa do INPEV operava com nove empresas parceiras para a reciclagem e cinco incineradoras (Basf, Cetrel, Clariant, Essencis e Haztec) localizadas em torno da região Sudeste do Brasil RJ, São Paulo e Bahia), como pode ser visto no mapa abaixo:

Figura 5 - Mapa do Brasil indicando 9 instalações de reciclagem

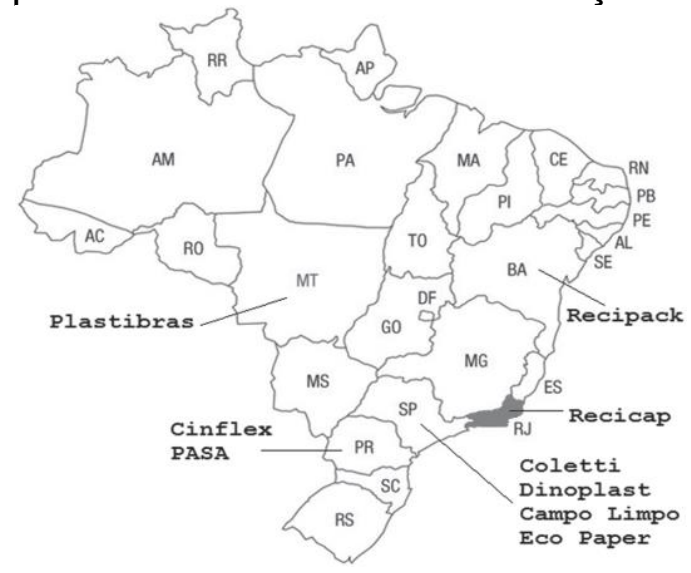

Fonte: Veiga, 2013, p. 29 
Conforme relata Oliveira e Camargo (2014), o INPEV também licencia e concede autorização a postos e centrais de recebimento, e equipados a receber e acondicionar as embalagens dos produtores. Esses postos ou centrais, num segundo momento, emitem uma ordem de coleta ao INPEV, ação operacionalizada a partir do uso de uma ferramenta de gestão da logística denominada Sistema de Informação de Centrais (SIC), que aciona transportadoras parceiras para a retirada das embalagens e posterior encaminhamento ao destino mais adequado (reciclagem ou incineração). Os galpões que servem para a operação dos postos e centrais de recebimento são cedidos ou construídos com recursos de parcerias firmadas entre 0 INPEV.

Comentam Nogueira e Dantas (2013), que, segundo a Associação Nacional de Defesa Vegetal (ANDAV) (2009), 100 milhões de litros de agrotóxicos são vendidos no Brasil anualmente, sendo que 300 litros permanecem nas embalagens vazias, oferecendo altos riscos aos que os manipulam e ao meio ambiente.

Ainda Veiga (2008), aponta que o mercado brasileiro de reciclagem contém grandes incertezas (sazonalidade e qualidade), com alguns compradores (concentrados nas grandes cidades) e numerosos vendedores (generalizados). Os custos da qualidade e do transporte fazer o uso de alguns materiais recicláveis não são benéficos em comparação com as matérias-primas equivalentes. Há muitas variáveis que devem ser levadas em consideração na tomada de decisão do uso do processo: tamanho (grandes e pequenas comunidades); material (tipos diferentes de materiais); indústria (cadeias de fornecimento diversificada); e assim por diante. A reciclagem pode não ser a ideal solução no âmbito de programas de logística reversa obrigatórias para pequenas comunidades.

A Lei 7.802/89, com a alteração da Lei 9.974/2000, estabelece penalidades (administrativa, civil e penal) aos que derem destinação inadequada às embalagens vazias, sendo pena de reclusão de 2 a 4 anos, além de multa (conforme artigo 15). E, de acordo com o artigo 17, a multa será de até 1000 (mil) vezes o Maior Valor de Referência - MVR, aplicável em dobro em caso de reincidência.

Com a logística reversa, segundo Cometti (2009), as embalagens que mais representam valor econômico são as de plástico, que são prensadas, enfardadas e 
enviadas a 10 recicladoras que mantém convênio com o INPEV, nos estados de MG, MG, PR, RJ e SP, as quais produzem 12 diferentes artigos: conduítes corrugados, embalagens para óleo lubrificante, dutos corrugados, luvas para emenda, economizadores de concreto, sacos plásticos para lixo hospitalar, tampas para embalagens de defensivos agrícolas, etc.

\section{METODOLOGIA}

O método de pesquisa permite ao pesquisador orientar seu trabalho no sentido de alcançar seu objetivo de maneira planejada quanto às observações, experimentos e análise de resultados e de informações. Aqui, de acordo com o objetivo proposto, o método consiste na realização de uma pesquisa bibliográfica apresentando a legislação e as discussões sobre a mesma por diferentes autores sob a ótica da consciência ambiental que deve existir dentro da cadeia da logística reversa das embalagens de agrotóxicos.

De acordo com Marconi e Lakatos (2010), a pesquisa bibliográfica, ou de fontes secundárias, tem a finalidade de colocar o pesquisador em contato direto com tudo o que foi escrito, dito ou filmado sobre determinado assunto, propiciando o exame de um tema sob novo enfoque ou abordagem, permitindo-se chegar a conclusões inovadoras.

Para Gil (2014), a principal vantagem da pesquisa bibliográfica está no fato de permitir ao pesquisador a cobertura de uma gama muito mais ampla de fenômenos e é indispensável nos estudos históricos. No presente caso, o levantamento histórico da legislação fez-se necessário.

Medeiros (2012) considera que a pesquisa bibliográfica significa 0 levantamento da bibliografia sobre o assunto que se deseja estudar e apresenta quatro etapas: identificação (levantamento do material bibliográfico); localização (de obras específicas); compilação (obtenção e reunião do material desejado) e fichamento (transcrição dos dados, anotações). Segue-se a análise e interpretação e a redação.

Portanto, fez-se uma revisão dos textos legais concernentes ao tratamento das embalagens de agrotóxicos, bem como da opinião de diversos autores que comentam essa legislação sob a ótica da consciência ambiental, a partir de revistas, 
artigos acadêmicos, teses, dissertações. Reconhece-se, a partir daí, falhas na execução da regulamentação legal, propondo-se continuidade dos estudos.

\title{
A LEGISLAÇÃO FRENTE À EXECUÇÃO DA PROPOSTA LOGÍSTICA REVERSA
}

O processo logístico reverso busca gerar valor aos produtos retornados e ser um diferencial competitivo frente às demais empresas. Trata-se de uma logística empresarial com possibilidade de obter ganhos com os resíduos, como a realimentação da cadeia de suprimentos. A proposta é que é possível crescimento econômico com preservação do meio ambiente (TOLEDO e GUEVARA, 2013) e (GONTIJO; DIAS; WERNER, 2010).

De acordo com Oliveira e Carmargo (2014), dados do INPEV (2013), indicam que $94 \%$ das embalagens primárias (as que entram em contato direto com o produto comercializado) são retiradas do campo e enviadas para a destinação ambientalmente correta. Com isso, o Brasil reafirma sua posição de referência em logística reversa de embalagens de agroquímicos.

Ainda que os números globais sejam confortantes, interessante o registro de Nogueira e Dantas (2013), sobre o resultado da pesquisa realizada no entorno do açude Epitácio Pessoa (Boqueirão, PB), localizado a 165km da capital do Estado, João Pessoa, e a 44km de Campina Grande (PB), sendo envolvidos um universo de 178 produtores rurais e uma amostra constituída por 36 produtores rurais:

\begin{abstract}
Quanto à destinação final das embalagens vazias de agrotóxicos, a maior parte $(53,1 \%)$ dos produtores rurais queima-as após o uso, no entanto $37,5 \%$ dos pesquisados afirmam que devolvem as embalagens ao comércio e $9,4 \%$ guardam essas embalagens para devolver ou jogam na serra como destino final. Além disso, muitas vezes a falta de informação e educação ambiental faz com que os agricultores (a maioria sem qualificação profissional) utilizem essas mesmas embalagens de forma totalmente irregular, transformando-as em recipientes para armazenamento de água e para uso domiciliar, fazendo com que os problemas de saúde pública se agravem devido à ingestão de produtos tóxicos. (NOGUEIRA; DANTAS, 2013, p. 29)
\end{abstract}

A par disso, Veiga (2013) afirma que a logística reversa é um processo reativo, com fatores imprevisíveis, eis que é iniciada pelo consumidor.

Ladeira, Maehler e Nascimento (2012), relatam que no caso do recolhimento das embalagens de defensivos agrícolas utilizadas nas plantações, exige-se uma cooperação que depende diretamente dos produtores rurais, que fazem parte de um elo da cadeia agrícola, como destacado por Inpev (2010). "A cooperação entre os 
elos da cadeia agrícola pode ser observada pelos fluxos de entrega ou logística convencional (matéria-prima, manufatura, distribuição e varejo) e pelos fluxos de, recolhimento ou logística reversa (coleta, transporte, desmantelamento e decomposição)." (LADEIRA, MAEHLER, NASCIMENTO, 2012, p. 158).

Ainda Ladeira, Maehler e Nascimento (2012), comentam que a inserção de legislação específica obrigando as empresas distribuidoras a realizar um recolhimento adequado e destinação das embalagens de defensivos agrícolas, por um lado, e um aumento na consciência ambiental dos agricultores, por outro, têm contribuído para a melhora nos índices de recolhimento de embalagens no Brasil. Assim, o recolhimento de embalagens vazias de defensivos agrícolas pode ser considerado ato da consciência ambiental do produtor rural.

Essa consciência ambiental necessita ser estimulada. Cometti (2009), registra que a partir de 2003, o INPEV junto com o Governo Federal passou a veicular campanhas educativas para orientação ao agricultor sobre suas responsabilidades no destino das embalagens de agrotóxicos, conforme quadro abaixo:

Quadro 1 - Campanhas educativas realizadas pelo INPEV e Governos

\begin{tabular}{|c|c|c|}
\hline ANO & CAMPANHA & OBJETIVO \\
\hline 2003 & $\begin{array}{l}\text { A natureza precisa de } \\
\text { você }\end{array}$ & \multirow{3}{*}{$\begin{array}{l}\text { Educar o agricultor quanto as suas responsabilidades previstas } \\
\text { na Lei Federal } 9.974 / 00 \text {. Possui formato didático baseado em } \\
\text { programas de auditório de perguntas e respostas e foi a } \\
\text { responsável pela criação do espantalho Olimpio, símbolo da } \\
\text { campanha. }\end{array}$} \\
\hline 2004 & Lava-me & \\
\hline 2005 & Devolva-me & \\
\hline 2006 & A natureza agradece & $\begin{array}{l}\text { Traz mensagens fortes sobre os pontos de maior atenção no } \\
\text { processo de destinação final, como a definição do papel do } \\
\text { agricultor no cumprimento de uma responsabilidade legal e a } \\
\text { entrega de todas as embalagens no local indicado na nota fiscal } \\
\text { de compra do produto. }\end{array}$ \\
\hline 2007 & Devolva certo & $\begin{array}{l}\text { Orientar agricultores e trabalhadores rurais sobre a forma } \\
\text { correta de proceder com a devolução das suas embalagens } \\
\text { vazias de defensivos agrícolas, evitando que os volumes saiam } \\
\text { do sistema formal de destinação final e entre em um sistema de } \\
\text { reciclagem ilegal e clandestina. }\end{array}$ \\
\hline 2009 & $\begin{array}{lccc}\text { Os dois lados } & \text { da } \\
\text { consciência } & & \end{array}$ & $\begin{array}{l}\text { Procura despertar a consciência principalmente daqueles que já } \\
\text { conhecem a legislação sobre a lavagem e devolução das } \\
\text { embalagens vazias, mas ainda não exercem sua } \\
\text { responsabilidade. }\end{array}$ \\
\hline
\end{tabular}

/Fonte: Cometti, 2009, p. 130 (elaborado com dados do INPEV, 2009) 
Miller e Sarder (2012), afirmam ainda que a logística reversa é um aspecto da sustentabilidade que precisa ser melhor compreendido pelos gestores públicos e a comunidade, para ajudar as empresar à inclinação à imagem do verde.

Garcia e Garcia (2001), colocam que avaliar impactos de políticas públicas não é tarefa simples, especialmente aquelas que se colocam na interface entre a produção, ambiente e saúde pública, como é o caso da legislação que propõe controlar o uso de agrotóxicos.

Segundo Melo et al (2013), pode-se entender a logística reversa como um meio de contribuição positiva para preservar o meio ambiente, além do que o processo de devolução e recuperação pode transformar-se em oportunidade de negócios. Como consequência, é evitado descartes ao meio ambiente, tendo a função de limpar os canais de distribuição. Estas são suas observações:

\begin{abstract}
Pode-se admitir então, que a logística reversa é uma das melhores estratégias para se aplicar nas empresas quando o assunto é minimizar impactos negativos, causados pelos resíduos de produtos ou processos ao meio ambiente. São, pois, as atividades reversas as responsáveis por recapturar valor aos produtos ou descartá-los corretamente, reduzindo assim seus impactos. Além de revelar um posicionamento de responsabilidade empresarial em relação ao meio ambiente, através da logística reversa, a organização continua responsável pelo seu produto mesmo após a entrega ao mercado de consumo e implanta uma nova cultura, qualificada pelo ciclo "reduza - reuse - recicle", também denominada "cultura ambientalista." (MELO et al, 2013, p. 10).
\end{abstract}

\title{
CONSIDERAÇÕES FINAIS
}

Nota-se que a logística reversa de embalagens de agrotóxicos, como determinada pela legislação, é um processo que contribui para a preservação do meio ambiente, evita danos à saúde pública e traz benefícios econômicos. No entanto, o mecanismo imposto pela legislação, que envolve responsabilidades compartilhadas entre os diversos elos da cadeia logística e seus auxiliares, tem início com a predisposição do agricultor (consumidor dos agrotóxicos), cuja cooperação influi diretamente nesse processo. A coleta e transporte das embalagens talvez seja a principal dificuldade enfrentada.

A colaboração e/ou compartilhamento de todos os envolvidos no processo, a veiculação de campanhas educativas, a atuação mais ativa do poder público, é o que pode incrementar e consolidar a conscientização ambiental, fazendo com que a efetividade daquilo que consta da legislação seja um ato de espontaneidade e de funcionalidade desse processo. 
Como foi demonstrado no artigo, todo o processo da logística reversa das embalagens de agrotóxicos proposto pela legislação e comentado pelos diferentes autores, não deixa de ser funcional e bem apresentado, com suas articulações muito bem definidas e capacidade de funcionamento.

Entretanto, sua operacionalidade depende dos atores, principalmente 0 produtor rural como primeiro elo da cadeia, que, se não contarem com uma estrutura de apoio funcional com capilaridade em toda área geográfica agricultável, certamente enfrentarão obstáculos para cumprir a legislação.

Por outro lado, se os órgãos governamentais não fizerem a sua parte no que tange a uma fiscalização mais intensa e abrangente, bem como não contribuir com a educação ambiental dos envolvidos, deixará à mercê da vontade dos participantes o cumprimento do que foi muito bem elaborado ou planejado em nossa legislação.

Este artigo acende uma luz para futuras investigações, com novas pesquisas como as de Nogueira e Dantas, 2013, aqui mencionada, para que se verifique outras localidades onde o cumprimento da lei deixa a desejar, seja pela falta de postos de coleta, pela infraestrutura de transporte ou até mesmo pela falta de informação adequada. É possível que se encontre falhas na legislação e/ou na execução da mesma pelos participantes da cadeia (o consumidor/produtor rural; as unidades de recebimento; o comerciante/distribuidor; o fabricante; o poder público), às vezes até involuntárias ou devido a pouca participação do poder público, haja vista a extensão territorial brasileira, a variabilidade e capilaridade dos usuários (produtores rurais).

\section{REFERÊNCIAS BIBLIOGRÁFICAS}

BRASIL. Decreto $n^{\circ}$ 24.114, de 12/04/1934. Aprova o Regulamento de Defesa Sanitária Vegetal. Disponível em < http://legislacao.planalto.gov.br/legisla/legislacao.nsf/Viw Identificacao/dec\%2024.1141934?OpenDocument> Acesso em 05 set. 2014

BRASIL. Decreto ํo 4.074, de 04/01/2002. Regulamenta a Lei no 7.802, de 11 de julho de 1989. Disponível em < https:/www.planalto.gov.br/ccivil 03/decreto/2002/d4074.htm> Acesso em 12 mar. 2015

BRASIL. Decreto ㄲo 98.816, de 11/01/1990. Regulamenta a Lei 7.802/1989 e dá outras providências. Disponível em < https://www.planalto.gov.br/ccivil 03/decreto/antigos/d98816.htm> Acesso em 12 mar. 2015

BRASIL. Lei Federal ㄲo 12.305, de 02/08/2010. Institui a Política Nacional de Resíduos Sólidos; altera a Lei no 9.605, de 12 de fevereiro de 1998; e dá outras providências. Disponível em < http://www.planalto.gov.br/ccivil_03/_ato2007-2010/2010/lei//12305.htm > Acesso em 05 set. 2014 


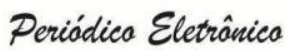 \\ Fórum Ambiental}

da Alta Paulista

Produtos, e dá outras Providências. Disponível em < http://www.planalto.gov.br/ccivil 03/leis/6360.htm> Acesso em 12 mar. 2015

BRASIL. Lei oㅜ 7.802/1989, de 11/07/1989. Dispõe sobre a pesquisa, a experimentação, a produção, a embalagem e rotulagem, o transporte, o armazenamento, a comercialização, a propaganda comercial, a utilização, a importação, a exportação, o destino final dos resíduos e embalagens, o registro, a classificação, o controle, a inspeção e a fiscalização de agrotóxicos, seus componentes e afins, e dá outras providências. Disponível em https://www.planalto.gov.br/ccivil 03/leis/17802.htm Acesso em 03 fev. 2015

BRASIL. Lei ำ 9.974, de 06/06/2000. Altera a Lei $n^{\circ} 7.802 / 1989$, que dispõe sobre a pesquisa, a experimentação, a produção, a embalagem e rotulagem, 0 transporte, 0 armazenamento, a comercialização, a propaganda comercial, a utilização, a importação, a exportação, o destino final dos resíduos e embalagens, o registro, a classificação, o controle, a inspeção e a fiscalização de agrotóxicos, seus componentes e afins, e dá outras providências. Disponível em < http://www.planalto.gov.br/ccivil 03/leis/L9974.htm> Acesso em 12 mar. 2015

BRASIL. Resolução CONAMA no 334, de 3 de abril de 2003. Dispõe sobre os procedimentos de licenciamento ambiental de estabelecimentos destinados ao recebimento de embalagens vazias de agrotóxicos. Disponível em < http://www.mma.gov.br/port/conamallegiabre.cfm?codlegi=356> Acesso em 20 mar. 2015

BRASIL. Resolução CONAMA no 465, de 05/12/2014. Dispõe sobre os requisitos e critérios técnicos mínimos necessários para o licenciamento ambiental de estabelecimentos destinados ao recebimento de embalagens de agrotóxicos e afins, vazias ou contendo resíduos. Disponível em < http:/www.mma.gov.br/port/conama/legiabre.cfm?codlegi=710> Acesso em 20 mar. 2015

COMETTI, José Luís Said. Logística reversa das embalagens de agrotóxicos no Brasil: um caminho sustentável? 2009. 152 f., il. Dissertação (Mestrado em Desenvolvimento Sustentável)-Universidade de Brasilia, 2009.

GARCIA, Eduardo Garcia. Avaliação das consequências da "Lei dos Agrotóxicos" nas intoxicações e nas classificações toxicológica e de potencial de periculosidade ambiental no período de 1990 a 2000. 2001. Tese de Doutorado. Universidade de São Paulo.

GIL, Antonio Carlos. Métodos e Técnicas de Pesquisa Social. 6 ed. São Paulo: Atlas, 2014

GONTIJO, Felipe Eugênio Kich; DIAS, Alexandre Magno de Paula; WERNER, Jaqueline. A logística reversa de ciclo fechado para embalagens PET. VI Congresso Nacional de Excelência em Gestão Energia, Inovação, Tecnologia e Complexidade para a Gestão Sustentável. Niterói-RJ, 5, 6, 7 ago 2010

LADEIRA, Wagner Junior; MAEHLER, Alisson Eduardo; NASCIMENTO, Luís Felipe Machado do. Logística reversa de defensivos agrícolas: fatores que influenciam na consciência ambiental de agricultores gaúchos e mineiros. Revista de Economia e Sociologia Rural, v. 50, n. 1, p. 157-174, 2012.

LEITE, Paulo Roberto. Logística Reversa: meio ambiente e competitividade. São Paulo: Prentice Hall, 2003.

MARCONI, Marina de Andrade; LAKATOS, Eva Maria. Técnicas de Pesquisa. 7 ed. São Paulo: Atlas, 2010

MAZZA, V.M.D.S. et al. Gestão de Resíduos Sólidos em Propriedades Rurais de Municípios do Interior do Estado do Rio Grande do Sul. Revista em Agronegócio e Meio Ambiente, Maringá, v. 7, n. 3, p. 683706, Sep 2014.

MEDEIROS, João Bosco. Redação Científica - A prática de fichamentos, resumos, resenhas. 11 ed. São Paulo: Atlas, 2012

MELO, Wederson Miranda et al. Logística Reversa de Embalagens de Agrotóxicos: um estudo de caso na cidade de Patos-MG. VIII Congresso Nacional de Excelência em Gestão, 8 e 9 de junho de 2012. ISSN 1984-9354

MILLER, Chad R.; SARDER, M. D. Public works policy implications of sustainable reverse logistics operations. Public Works Management \& Policy, p. 1087724X11429044, 2011. 
MOTTA, Wladmir Henriques. Análise do Ciclo de Vida e Logística Reversa. X SEGeT 2013 Simpósio de Excelência em Gestão e Tecnologia. Gestão e Tecnologia para a Competitividade. 23,24,25 out/2013

NOGUEIRA, Viviane Barreto Motta; DANTAS, Renilson Targino. Gestão Ambiental de Embalagens Vazias de Agrotóxicos. Revista Tema. v.14, n. 20/21, jan/dez/2013, ISSN 2175-9553 (Revista online do CESED - Centro de Ensino Superior e Desenvolvimento.

OLIVEIRA, Andréa Leda Ramos de; CAMARGO, Samira Gaiad Cibim de. Logística Reversa de Embalagens de Agroquímicos: identificação dos determinantes de sucesso. Interciencia, Caracas, v. 39, n. 11, p. $780-787,112014$.

TOLEDO, Aline Beatriz; GUEVARA, Arnoldo José de Hoyos. Logística Reversa. Núcleo de Estudos do Futuro, PUC, SP, Brasil, 2013.

VEIGA, Marcelo M. Analysis of efficiency of waste reverse logistics for recycling. Waste Management \& Research 31(10) Supplement 26-34 (C) The Author(s) 2013 Reprints and permissions: Downloaded from wmr.sagepub.com at UNIV ESTDL PAULISTA DE MESQIT on March 30, 2015 sagepub.co.uk/journalsPermissions.nav.

VEIGA, Marcelo Motta. Flaws in Brazilian take-back program for pesticide containers in a small rural community. Management Research News, (2008), Vol. 32 Iss 1 pp. $62-77$ 